\title{
COVID-19 - Challenges ahead of vaccination in immunocompromised patients
}

\author{
Pankaj Bansal ${ }^{1}$ and Amandeep Goyal ${ }^{2 *}$ \\ ${ }^{1}$ Mayo Clinic Health System, Eau Claire, USA \\ ${ }^{2}$ University of Kansas Medical Center, Kansas City, USA
}

\begin{abstract}
A novel strain of coronavirus - SARS-CoV-2 - was first detected in December 2019 in Wuhan, a city in China's Hubei province, after an outbreak of pneumonialike symptoms. The virus has now spread to over 200 countries and territories across the globe and was characterized as a pandemic by the World Health Organization (WHO) on 11 March 2020. To date, there is no proven effective treatment for the COVID-19 with ongoing trials on anti-viral and immunosuppressive therapies. Due to the highly contagious nature of COVID-19, the most promising way to contain the infection is by the development of a vaccine. Scientists all over the world are working tirelessly to develop a vaccine with several trials already undergoing and reaching phase 2 . If and once a safe and effective vaccine is available, essential evidence-based considerations will be needed for the high-risk immunocompromised population. In this short summary, we are interpreting the current literature pertaining to vaccinations in patients on immunosuppressive medications and suggest how to implement management strategies in these patients once a vaccine is available for COVID-19.
\end{abstract}

\section{Commentary}

The world is in the midst of an unprecedented crisis caused by the severe acute respiratory syndrome coronavirus 2 (SARS-CoV-2) disease 2019 (COVID-19) which was first reported in December 2019. According to the World Health Organization situation report, as of July 15, 2020, 13,150,645 cases have been confirmed with 574,464 deaths globally [1]. To date, there is no definitively-proven effective treatment for the COVID-19 with trials ongoing on anti-viral and immunosuppressive therapies. Scientists all over the world are running a race against the time to find a vaccine with several trials already undergoing and reaching phases 2 and 3.

There has been substantial evolution in the development of vaccines since 1796 when Edward Jenner demonstrated immunity to smallpox after inoculating a child with the vaccinia virus [2]. Today, vaccines are considered one of the most cost-effective devices for saving life. The introduction of foreign antigens leading to activation of the innate immune system which then activates and regulates the adaptive immune system resulting in the production of protective antibodies is the basis of vaccination. Despite their origin more than 200 years ago, and significant advancements leading to the eradication of diseases such as smallpox and polio, there are still gaps in our knowledge and understanding of the immunological mechanisms of vaccines, which can be highlighted by failure to develop vaccines against global pandemics such as the human immunodeficiency virus (HIV).

Infections, some of which are vaccine-preventable, are one of the most common causes of mortality in patients with autoimmune diseases such as rheumatoid arthritis (RA), who are immunocompromised due to immune dysfunction caused by the disease, as well as due to iatrogenic immunosuppression [3,4]. Live-attenuated vaccines are contraindicated in patients who are on strong immunosuppressive medications and shall be given at least 2 weeks before initiation of immunosuppression. Influenza and pneumococcal vaccines which are inactivated vaccines are strongly recommended in patients with autoimmune rheumatic diseases [5-7]. However, there are several concerns with inactivated vaccines as well in these patients including the effects of immunosuppressive medications on the vaccines.

Although there are theoretical concerns of exacerbation of the underlying autoimmune disease due to the immune response to vaccines, limited data so far has been reassuring and has not shown vaccineassociated changes in disease activity of autoimmune diseases including systemic lupus erythematosus, dermatomyositis, polymyositis, and Sjogren syndrome [8-12]. The production of neutralizing antibodies to neoantigens can be suppressed by medications suppressing humoral immunity [13]. Studies in the past have shown reduced humoral response to seasonal influenza and pneumococcal vaccines due to methotrexate, rituximab and abatacept, and to Hepatitis $B$ vaccine in patients taking tumor-necrosis factor inhibitors [14-21]. There is conflicting data about the effect of tumor necrosis factor inhibitors on immunogenicity to influenza and pneumococcal vaccines [22-26]. Interleukin-6 inhibitors (tocilizumab) and Janus kinase inhibitors (tofacitinib) were not associated with a diminished immune response to pneumococcal and influenza vaccines $[27,28]$.

Further, in patients with RA, temporary discontinuation of methotrexate for two weeks after vaccination was shown to be associated with significant improvement in immunogenicity of the seasonal influenza vaccine without an increase in the rheumatoid arthritis disease activity [29]. The suppressive effect of methotrexate has been proposed

*Correspondence to: Amandeep Goyal, University of Kansas Medical Center, Kansas City, USA, Tel: 7404348258; E-mail: agoyal3@kumc.edu

Key words: SARS-CoV-2, COVID-19, immunocompromised, vaccination

Received: June 16, 2020; Accepted: August 07, 2020; Published: August 11, 2020 
to be secondary to its interaction with the B-cell activation factor (BAFF) leading to an increase in immunosuppressive adenosine and regulatory B-cells, hence suppressing humoral immune response [30]. Park, et al. suggested holding methotrexate for 2 weeks after seasonal influenza vaccination to improve vaccine immunogenicity [31]. Similarly, Bingham, et al. suggested administration of polysaccharide and primary immunization before rituximab infusions to maximize the humoral response to the vaccine [32].

There are limitations with the data available so far. While the current literature suggests a decrease in the immunological response in patients continuing immunosuppressive therapy after the vaccination, no information is available about the transformation of this data to the actual clinical setting, such as difference in incidences of the viral infection by withholding or continuing the immunosuppressive therapy after the vaccination. Immune response to vaccines is a surrogate marker and while it may not transform into protection against the disease, stronger seroprotection may theoretically be associated with better protection against the viral infection.

Similar strategies may be needed for the SARS-COV2 vaccine if and when it becomes available. To better protect the vulnerable immunocompromised patients, aiming for better seroprotection by using practices proven to be effective and safe such as holding methotrexate for 2 weeks after the vaccination, and vaccination before rituximab infusions may be considered until further clinical trials are available about the effects of immunosuppression on the vaccine once it is available.

\section{Financial disclosure and Conflict of interest statement}

We confirm that the authors have no financial disclosures, competing interests and conflict of interest. The study has not received any financial support or other benefits from commercial sources for the work reported on in the manuscript. The manuscript is being submitted for consideration in publication of OA Text journals. The manuscript represents original work of the authors and identical or similar work has not been published or submitted for publication elsewhere.

\section{Author contributions}

All authors have made significant contribution to the study including writing initial manuscript, reviewing literature and revising manuscript. All authors have read and approved the final version of the manuscript, which is being submitted by the corresponding author on behalf of authors.

\section{Ethics approval}

The mayo clinic institutional review board (IRB) acknowledges that based on the responses submitted for this new activity through the Mayo Clinic IRBe Human Subjects Research Wizard Tool, and in accordance with the Code of Federal Regulations, 45 CFR 46.102, the above noted activity does not require IRB review.

\section{Data sharing statement}

There are no data in this work.

\section{Acknowledgements}

We acknowledge that this letter is ahead of its time with a vaccine for SARS-CoV-2 still in the infant stages of development. However, when the world is going through a crisis, we need to be better prepared by thinking ahead of time and being proactive rather than reactive.

\section{References}

1. https://www.who.int/emergencies/diseases/novel-coronavirus-2019/situation-reports

2. Jenner E (1799) History of the inoculation of the cow-pox: Further observations on the variole vaccine, or cow-pox. Med Phys J 1: 313-318.

3. Wolfe F, Mitchell DM, Sibley JT, Fries JF, Bloch DA, et al. (1994) The mortality of rheumatoid arthritis. Arthritis Rheum 37: 481-494.

4. Wakabayashi A, Ishiguro T, Takaku Y, Miyahara Y, Kagiyama N, et al. (2018) Clinical characteristics and prognostic factors of pneumonia in patients with and without rheumatoid arthritis. PLoS One 13: $\mathrm{e} 0201799$.

5. Singh JA, Saag KG, Bridges SL Jr, Akl EA, Bannuru RR, et al. (2016) 2015 American college of rheumatology guideline for the treatment of rheumatoid arthritis. Arthritis Rheumatol 68: 1-26.

6. Rubin LG, Levin MJ, Ljungman P, Davies GE, Avery R, et al. (2014) 2013 IDSA clinical practice guideline for vaccination of the immunocompromised host. Clin Infect Dis 59: 144.

7. Furer V, Rondaan C, Heijstek MW, Agmon-Levin N, van Assen S, et al. (2020) 2019 update of EULAR recommendations for vaccination in adult patients with autoimmune inflammatory rheumatic diseases. Ann Rheum Dis 79: 39-52

8. Kuruma KA, Borba EF, Lopes MH, de Carvalho JF, Bonfá E (2007) Safety and efficacy of hepatitis B vaccine in systemic lupus erythematosus. Lupus 16: 350-354.

9. Nakafero G, Grainge MJ, Myles PR, Mallen CD, Zhang W, et al. (2019) Association between inactivated influenza vaccine and primary care consultations for autoimmune rheumatic disease flares: a self-controlled case series study using data from the Clinical Practice Research Datalink. Ann Rheum Dis 78: 1122-1126.

10. Pasoto SG, Ribeiro AC, Viana VS, Leon EP, Bueno C, et al. (2013) Short and longterm effects of pandemic unadjuvanted influenza $\mathrm{A}(\mathrm{H} 1 \mathrm{~N} 1)$ pdm09 vaccine on clinical manifestations and autoantibody profile in primary Sjögren's syndrome. Vaccine 31: 1793-1798.

11. Mok CC, Ho LY, Fong LS, To CH (2013) Immunogenicity and safety of a quadrivalent human papillomavirus vaccine in patients with systemic lupus erythematosus: a casecontrol study. Ann Rheum Dis 72: 659-664.

12. Shinjo SK, de Moraes JC, Levy-Neto M, Aikawa NE, de Medeiros Ribeiro AC, et al (2012) Pandemic unadjuvanted influenza A (H1N1) vaccine in dermatomyositis and polymyositis: immunogenicity independent of therapy and no harmful effect in disease. Vaccine 31: 202-206.

13. Subesinghe S, Bechman K, Rutherford AI, Goldblatt D, Galloway JB (2018) A systematic review and metaanalysis of antirheumatic drugs and vaccine immunogenicity in rheumatoid arthritis. J Rheumatol 45: 733-744.

14. Hua C, Barnetche T, Combe B, Morel J (2014) Effect of methotrexate, anti-tumor necrosis factor $\alpha$, and rituximab on the immune response to influenza and pneumococcal vaccines in patients with rheumatoid arthritis: a systematic review and meta-analysis Arthritis Care Res 66: 1016-1026.

15. Westra J, van Assen S, Wilting KR, Land J, Horst G, et al. (2014) Rituximab impair immunoglobulin (Ig)M and IgG (subclass) responses after influenza vaccination in rheumatoid arthritis patients. Clin Exp Immunol 178: 40-47.

16. van Assen S, Holvast A, Benne CA, Posthumus MD, van Leeuwen MA, et al. (2010) Humoral responses after influenza vaccination are severely reduced in patients with rheumatoid arthritis treated with rituximab. Arthritis Rheum 62: 75-81.

17. Ribeiro AC, Laurindo IM, Guedes LK, Saad CG, Moraes JC, et al. (2013) Abatacept and reduced immune response to pandemic 2009 influenza A/H1N1 vaccination in patients with rheumatoid arthritis. Arthritis Care Res 65: 476-480.

18. Alten R, Bingham CO 3rd, Cohen SB, Curtis JR, Kelly S, et al. (2016) Antibody response to pneumococcal and influenza vaccination in patients with rheumatoid arthritis receiving abatacept. BMC Musculoskelet Disord 17: 231.

19. Migita K, Akeda Y, Akazawa M, Tohma S, Hirano F, et al. (2015) Effect of abatacept on the immunogenicity of 23-valent pneumococcal polysaccharide vaccination (PPSV23) in rheumatoid arthritis patients. Arthritis Res Ther 17: 357.

20. Oren S, Mandelboim M, Braun-Moscovici Y, Paran D, Ablin J, et al. (2008) Vaccination against influenza in patients with rheumatoid arthritis: the effect of rituximab on the humoral response. Ann Rheum Dis 67: 937-941.

21. Gisbert JP, Villagrasa JR, Rodríguez-Nogueiras A, Chaparro M. (2012) Efficacy of hepatitis B vaccination and revaccination and factors impacting on response in patients with inflammatory bowel disease. Am J Gastroenterol 107: 1460-1466.

22. Kivitz AJ, Schechtman J, Texter M, Fichtner A, de Longueville M, et al. (2014) Vaccine responses in patients with rheumatoid arthritis treated with certolizumab pegol: results from a single-blind randomized phase IV trial. J Rheumatol 41: 648-657. 
23. Hagihara Y, Ohfuji S, Watanabe K, Yamagami H, Fukushima W, et al. (2014) Infliximab and/or immunomodulators inhibit immune responses to trivalent influenza vaccination in adults with inflammatory bowel disease. J Crohns Colitis 8: 223-233.

24. Kobie JJ, Zheng B, Bryk P, Barnes M, Ritchlin CT, et al. (2011) Decreased influenzaspecific B cell responses in rheumatoid arthritis patients treated with anti-tumor necrosis factor. Arthritis Res Ther 13: R209.

25. Fomin I, Caspi D, Levy V, Varsano N, Shalev Y, et al. (2006) Vaccination against influenza in rheumatoid arthritis: the effect of disease modifying drugs, including TNF alpha blockers. Ann Rheum Dis 65: 191-194.

26. Elkayam O, Bashkin A, Mandelboim M, Litinsky I, Comaheshter D, et al. (2010) The effect of infliximab and timing of vaccination on the humoral response to influenza vaccination in patients with rheumatoid arthritis and ankylosing spondylitis. Semin Arthritis Rheum 39: 442-447.

27. Mori S, Ueki Y, Hirakata N, Oribe M, Hidaka T, et al. (2012) Impact of tocilizumab therapy on antibody response to influenza vaccine in patients with rheumatoid arthritis. Ann Rheum Dis 71: 2006-2010.
28. Winthrop KL, Silverfield J, Racewicz A, Neal J, Lee EB, et al. (2016) The effect of tofacitinib on pneumococcal and influenza vaccine responses in rheumatoid arthritis. Ann Rheum Dis 75: 687-695.

29. Park JK, Lee YJ, Shin K, Ha Y-J, Lee EY, et al. (2018) Impact of temporary methotrexate discontinuation for 2 weeks on immunogenicity of seasonal influenza vaccination in patients with rheumatoid arthritis: a randomised clinical trial. Ann Rheum Dis 77: 898-904.

30. Park JK, Lee YJ, Bitoun S, Winthrop KL, Choi Y, et al. (2019) Interaction between B-cell activation factor and methotrexate impacts immunogenicity of seasonal influenza vaccination in patients with rheumatoid arthritis. Ann Rheum Dis 78: 282-284.

31. Park JK, Choi Y, Winthrop KL, Song YW, Lee EB (2019) Optimal time between the last methotrexate administration and seasonal influenza vaccination in rheumatoid arthritis: post hoc analysis of a randomised clinical trial. Ann Rheum Dis 78: 1283-1284.

32. Bingham CO 3rd, Looney RJ, Deodhar A, Halsey N, Greenwald M, et al. (2010) Immunization responses in rheumatoid arthritis patients treated with rituximab: results from a controlled clinical trial. Arthritis Rheum 62: 64-74.

Copyright: @2020 Bansal P. This is an open-access article distributed under the terms of the Creative Commons Attribution License, which permits unrestricted use, distribution, and reproduction in any medium, provided the original author and source are credited. 